Recibido: 18-octubre-2013

Aceptado: 21-octubre-2013

\title{
LA MUERTE DE ARTEMIO CRUZ Y EL ÚLTIMO ENGAÑO DE LOS IDEALES DE LA REVOLUCIÓN MEXICANA
}

LUIS A. AGUILAR MONSALVE

Universidad San Francisco de Quito 


\section{RESUMEN}

El objetivo de este trabajo, es examinar la novela La Muerte de Artemio Cruz de Carlos Fuentes, con miras a mostrar cómo Artemio Cruz personifica la última traición de los ideales de la Revolución Mexicana.

Demuestra cómo esta novela cierra este ciclo básico de protesta contra los abusos de la dictadura porfirista, y contra los privilegios de que gozaban ciertas élites superiores: el clero, los industriales o los terratenientes.

El autor contextualiza su investigación tomando como marco el denominado grupo del boom literario latinoamericano y también contextualiza La muerte de Artemio Cruz con respecto a otras obras del propio Carlos Fuentes.

Palabras clave: México, revolución, porfiriato, traición, boom latinoamericano, novela.

\section{ABSTRACT}

The aim of this paper is to examine the novel The Death of Artemio Cruz by Carlos Fuentes in order to show how Artemio Cruz embodies the ultimate betrayal of the ideals of the Mexican Revolution.

It demonstrates how this novel closes its basic cycle of protest against the abuses of the Diaz dictatorship and against the privileges enjoyed by certain superior elites: the clergy, industrialists or the landowners.

The author contextualizes his research taking as reference a group called the Latin American literary Boom and contextualizes the Death of Artemio Cruz with respect to other of his works.

Keywords: Mexico, revolution, Porfirio Diaz, betrayal, boom Latin American, novel. 
El propósito de esta investigación es examinar La Muerte de Artemio Cruz (1962) de Carlos Fuentes, con miras a mostrar cómo Artemio personifica la última traición de los ideales de la Revolución Mexicana.

El plan de la investigación será describir el contexto en el cual se desarrolla el personaje de Artemio, y luego revelar cómo Fuentes lo utiliza como un análogo para el éxito de los objetivos de la revolución por un lado, y para el fracaso de los ideales de la sublevación por el otro asimismo, es necesario indicar que Carlos Fuentes dentro de la cultura es uno de los bastiones más fuertes con los que cuenta la nueva literatura latinoamericana a partir de los años 50.

[E]n 1958, publica La región más transparente, un libro básico para comprender y dividir la literatura hispanoamericana del pasado con la nueva y transformadora narrativa del presente. Esta novela es el reflejo de la realidad mexicana que ha fracasado al seguir a los ideales y premisas de la Revolución Mexicana de 1910 y, el trastorno que se ha dado de los cincuenta en adelante, debido a la existencia de una nueva burguesía dependiente económicamente del influjo paternalista estadounidense. (Aguilar Monsalve, Breve historia..., p. 239)

El título se refiere a uno de los libros histórico-documentales del ensayista mexicano Alfonso Reyes, cuyo enunciado es Visón de Anáhuac (1951). En el primer capítulo escribe "Viajero: has llegado a la región más transparente...la era de los descubrimientos [y de los cambios]" (Reyes, Visión..., p. 9).

La novela de Fuentes está considerada como el inicio del boom - nombre que las casas editoriales barcelonesas dieron a esta nueva producción reivindicadora y revolucionariapor tener una nueva actitud elitista, experimental y libresca. Igualmente, por engendrar develamientos sustanciales formarán parte de este fenómeno literario. También ocupó en este quehacer literario a muchos escritores de este hemisferio que cuestionaban el statu quo de la estructura literaria y aún del lenguaje como Ernesto Sábato, Juan Rulfo, Alejo Carpentier o Juan Carlos Onetti, considerados igualmente iniciadores de aquella nueva actitud innovadora.

Pero, a partir de los 60, escritores como Julio Cortázar, Carlos Fuentes, Gabriel García Márquez o Mario Vargas Llosa -los cuatro grandes-, entre otros, fueron los que pusieron las pautas necesarias para que esta literatura llegue a ser considerada como una de las grandes dentro de la literatura universal.

Con La región más transparente el escritor vuelve

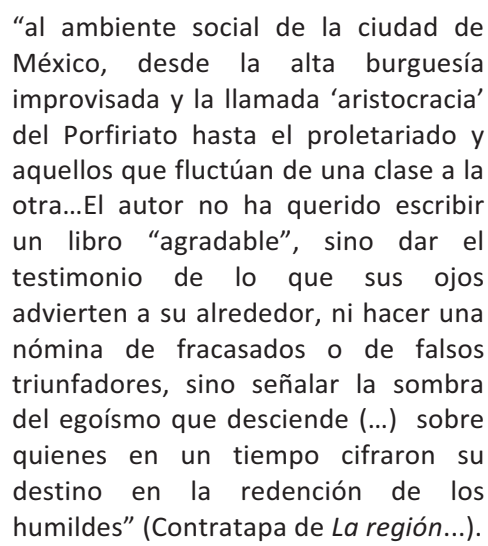

Asimismo, con La región más transparente se hace un registro prolongado de lo que es la sociedad 
mexicana y en ella se encuentran meandros entretejidos dentro del país, recovecos que definen inquietudes socio políticas que arrastran lo mítico y lo real de la Revolución. Desde Los de abajo (1916) del médico-escritor Mariano Azuela que fue uno de los iniciadores de las novelas de la revolución. Los de abajo sobresale por su valor histórico-ideológico-literario, además de presentar los efectos atroces de un conflicto bélico.

Agustín Yáñez saca a luz Al filo del agua (1947) y exhibe algunos de los efectos en gestación causados por la Rebelión de 1910 dentro del cosmos mexicano; la sublevación ya bien arraigada dentro de la sociedad mexicana apunta su madurez progresiva y, el pueblo mexicano, vive bajo los efectos del cambio sentidos por más de una treintena de años. En México la situación de las clases sociales, parte intrínseca de la revolución, se ha transformado significativamente: la recomposición de las oligarquías, la fragmentación de la clase trabajadora y la exagerada religiosidad que su autor pone en tela de denuncia, hacen de esta novela una de las más significativas en el tríptico mexicano: Los de abajo -Al filo de agua- La muerte de Artemio Cruz.

Esta última es la que cierra este ciclo básico de protesta contra los abusos de la dictadura porfirista, y contra los privilegios de que gozaban ciertas élites superiores: el clero, los industriales o los terratenientes.

Ahora bien, La muerte de Artemio Cruz, novela a la que estamos abordando, es una obra

esencial dentro de las nuevas estructuras de corte moderno que se iban implantando en la década de los sesenta. Su recorrido narrativo es también una mezcla de búsquedas paralelas, cuyo fin parece ser el averiguar exactamente quién era el personaje principal llamado Artemio Cruz y qué papel fundamental ejercía este individuo en la novela, en la caracterización del México milenario y de su rol regenerador dentro de la producción hispanoamericana (Aguilar Monsalve, pp. 240-241).

Artemio es un emblema del revolucionario exitoso que se ha apropiado de los objetivos de la revolución para alcanzar beneficios económicos y un poder personal más generalizado. Para expresarlo de otra manera, un grupo de oligarcas (disfrazados como pequeños burgueses) ha sustituido a otro, y para cuando la nueva oligarquía ha sido establecida, uno difícilmente pueda distinguir al nuevo régimen del antiguo, donde la masa de personas está afectada. Cualquiera de los ideales de redistribución de la propiedad que pueden haber estado contenidos en los corazones de los revolucionarios son suplantados por intereses más inmediatos y provincianos. El punto de conflicto para México se da entre lo que emerge por haber sido la estructura totalmente represiva de peleoneros de Díaz y la burguesía revolucionaria para la cual la tortura física puede ser repelente pero la masa de campesinos mexicanos en cuyo nombre se libró la revolución es también una idea tardía. En este sentido, Hart comenta que uno de los factores principales en la revolución de 1910 fue el "desencanto de la pequeña burguesía con dictadura y cacicazgo " (Hart, p. 9). Díaz había sido más gentil, posiblemente, el campesinado (el cual fue despojado y reprimido) y la burguesía jamás habrían peleado en el mismo bando. Así luego de la revolución la gentileza de la burguesía 
mantuvo al campesinado tan oprimido materialmente como nunca antes. Sin embargo, el símbolo de una revolución común retuvo el poder con aliados de diferentes clases sociales lo suficiente para que los mejores educados y financiados se atrincheren en la estructura de poder del México pos revolucionario.

El por qué esto es una traición que personifica Artemio es que la exitosa rebelión contra Díaz mostró a los revolucionarios con opciones claras cómo se llevarían a cabo los objetivos de la revolución. En parte, las opciones surgieron del hecho que, como señala Hart, clases sociales dispares, "el campesinado, obreros industriales y urbanos, pequeña burguesía, y elites provinciales expresaron objetivos revolucionarios distintos durante la lucha. Sus visiones incluían objetivos violentamente contradictorios así como también otros reconciliables" (Hart, p. 2). La rebelión "multi-clase", en caso de tener éxito, produciría inevitablemente un nuevo orden que sería confrontado con objetivos conflictivos provenientes de su inicio.

El hecho que Artemio, ambicioso como es, percibe más oportunidades en aliarse con la burguesía orientada a resultados materiales, muestra que estaba, después de todo, interesado menos en la revolución "pura" que en asegurar una reivindicación por propósitos revolucionarios personales. Se transforma en un actor clave en la consolidación de la nueva oligarquía de hombres que supuestamente llegan a la posición por su propio esfuerzo. O, como expresa Hart, "El Nuevo régimen, en conjunto con el rápido crecimiento de la economía capitalista, ha dado poder a una burguesía renaciente y dejado a las clases mexicanas obreras en condiciones de una pobreza económica deplorable" (Hart, p. 16). Artemio es parte de ese renacer, que personifica, en efecto, un egoísmo miserable que solo se remedia con una muerte dolorosa y despreciable.

En varios puntos del libro Fuentes describe el hombre que Artemio Cruz está a punto de convertirse debido a sus motivaciones y acciones cómo Artemio personifica el proceso de traición de sus ideales.

El primer episodio tiene lugar cuando Artemio llega a la finca de Bernal, lanzado por un lado desde la tardía victoria revolucionaria y por el otro llevando un mensaje de muerte al patriarca de la finca, quien había sido un miembro de la oligarquía ahora despojada. Don Gamaliel Bernal es de la vieja escuela en más de un sentido; ve en el joven -que es probable se convierta en su yerno- el impulso hacia la corrupción que caracterizará a una revolución que siempre ha encontrado repugnante y se da cuenta que se convertirá en un completo fraude. Don Gamaliel puede perder su propio acceso al poder (ha visto a su hijo unirse a los revolucionarios), pero tiene la premonición suficiente para ver que México, también, perderá su alma por hombres tales como Artemio.

Artemio Cruz. Así se llamaba, entonces, el nuevo mundo surgido de la guerra civil; así se llamaban quienes llegaban a sustituirlo. Desventurado país - se dijo el viejo mientras caminaba, otra vez pausado, hacia la biblioteca y esa presencia indeseada pero fascinante -; desventurado país que cada generación tiene que destruir a los antiguos poseedores y sustituirlos por nuevos amos, tan rapaces y ambiciosos como los anteriores. El viejo se imaginaba a sí mismo como el producto final de una 
civilización peculiarmente criolla: la de los déspotas ilustrados. Se deleitaba pensándose como un padre, a veces duro, al cabo proveedor y siempre depositario de una tradición del buen gusto, de cortesía, de cultura... No mencionó siquiera las verdaderas razones de su visita. Don Gamaliel aceptó que era mejor así: quizás el recién llegado comprendía las cosas con tanta sutileza como él, aunque sus motivaciones fueran más poderosas: la ambición -el viejo hombre sonrió al recordar ese sentimiento, para él sólo palabra-; el impulso inmediato a cobrar los derechos ganados con sacrificio, la lucha, las heridas, esa cicatriz de sable en la frente. $Y$ en los ojos del extraño estaba escrito lo que Don Gamaliel sabía leer (Fuentes - La Muerte de Artemio Cruz, p. 50).

La batalla que hace a Artemio un héroe es otro ejemplo en el cual este personaje tiene una oportunidad de comportarse como un verdadero revolucionario, pero no lo hace. $\mathrm{Ha}$ intentado retirarse en medio de la batalla, pero cuando la fortuna de los escuadrones cambia, es mal comprendido por las tropas, confundido con un héroe, $y$ promovido. Aprovecha su éxito en la revolución en un trabajo como negociador entre compañías estadounidenses con intereses en México y servicios públicos mexicanos nacionales como el ferrocarril, asumiendo un poder creciente en parte porque toma la oportunidad para acusar anarquistas o porque desacredita a rivales políticos y económicos. "Obtuvo con mi ayuda", -recuerda Artemio-,

... la concesión para construir esa carreteras en Sonora... Incluso lo ayudé para que le aprobaran un préstamo... [para] que la carretera... [pasara] por los distritos de riego que le compré a los ejidatarios. Acabo de informarme de que el lámpara también compró sus tierritas por aquel rumbo y piensa desviar el trozo de la carretera para que pase por sus propiedades... -iPero qué cerdo! Tan decente que parece -...ya sabes; metes unos cuantos chismes en tu columna hablando del inminente divorcio de nuestro prohombre. Muy suavecito, no más para que se nos asuste"

(Fuentes - La Muerte de Artemio Cruz, pp. 87-88).

Esto es típico de los juegos de poder de Artemio, y por supuesto son vulgares en el lenguaje y en su absoluto desprecio del contenido emocional o psicológico de los seres humanos, tan ordinario como el paso hecho por los nuevos poderoso en México para quedarse a cargo de la explotación de los agricultores que habían sido anteriormente manejados por la oligarquía de Díaz, y para consolidar el poder mediante el ejercicio de la codicia que don Gamaliel había reconocido en Artemio desde el principio.

Ambicioso como es, Artemio es seducido por los frutos de la revolución luego que esta en sí misma tiene éxito, y su experiencia de ella se vuelve análoga a la vivencia de México luego de la destitución de Díaz. Esto está entre líneas en una reflexión hecha por Artemio en su lecho de muerte, cuando sabe que está por llegar su final y que su familia está distanciada de él. Existe una dicotomía de sentimientos como él reflexiona sobre su éxito frente a la traición de la revolución triunfante.

¿Qué saben ellos, Catalina, el cura, Teresa, Gerardo? ¿Qué importancia van a tener sus aspavientos de duelo, o las expresiones de honor que aparecerán en los periódicos? ¿Quién tendrá la honradez de decir, como yo lo digo ahora, que mi único amor ha sido la posesión de las cosas, su propiedad sensual? Eso es lo que quiero. La sábana que acaricio. $Y$ todo 
lo demás, lo que ahora pasa frente a mis ojos. . Tierra. Tierra que puede traducirse en dinero (Fuentes - $L a$ Muerte de Artemio Cruz, pp. 139-40).

¿Quién dice que el delito no paga? La evidencia está a la vista, incluso si la muerte le llega a Artemio como a otros hombres. Artemio traicionó los ideales de la revolución para tener éxito. Se ha beneficiado de la traición, material y sensualmente, no emocionalmente. Entonces se resiente de enredos emocionales -qué saben los demás- y goza en la riqueza. Artemio tiene la apariencia de dignidad social, y desde luego todos los accesorios de la riqueza que hacen posible tal apariencia. Pero oculta un resentimiento injurioso y desesperación, y es en este contexto que se inserta otra reflexión y en el proceso traiciona la filosofía que Artemio ha asimilado desde los días de resplandor de la revolución.

Viva México, jijos de su rechingada: tristeza, madrugada, tostada, tiznada, guayaba, el mal dormir, hijos de la palabra. Nacidos de la chingada, muertos en la chingada, vivos por pura chigadera: vientre y mortaja, escondidos en la chingada. Ella da la cara, ella reparte la baraja. . . Eres quien eres porque supiste chingar y no te dejaste chingar... crees que con ella regresarás a los orígenes: ¿a cuáles orígenes? No tú: nadie quiere volver a la edad de oro mentirosa, a los orígenes siniestros, al gruñido bestial. . . al terror sin nombre del origen. . . crees que con ella caminarás hacia adelante, te afirmarás: ¿a cuál futuro? No tú: nadie quiere caminar cargado de la maldición, de la sospecha, de la frustración, del resentimiento, del odio, de la envidia, del rencor, del desprecio, de la inseguridad, de la miseria, del abuso, del insulto, de la intimidación, del falso orgullo, del machismo, de la corrupción de tu chingada chingada... (Fuentes - La Muerte de Artemio Cruz, pp. 144-46).
Tal bilis está obligada a producir un cáncer gástrico, y es esta enfermedad en el México que Fuentes está examinando, en México, a través del microscopio revolucionario de la vida de Artemio revolucionario, como parte de una facción de la guerra civil, y como nuevo rico terrateniente en la agonía de la enfermedad terminal.

No es exagerado decir que en la persona de Artemio, México está muriendo, también, o en todo caso, que la revolución murió para la revolución a favor de su búsqueda de posesiones materiales. Está muriendo, parece sugerir Fuentes, de los excesos que algunos de sus habitantes se han vuelto en contra de otros. Artemio ha utilizado a terceros antes que pudieran usarlo a él. Se está muriendo del éxito de los objetivos a corto plazo y los fracasos de las necesidades a largo plazo. En este sentido, Fuentes toma la simbología de la palabra de Artemio como el símbolo del destino pos revolucionario de México. Además, Fuentes comenta, en relación a la situación de ser en la cual él ve a México, "El lenguaje de los mexicanos surge de extremos abismales de poder e impotencia, dominación y resentimiento. Es el espejo de una superabundancia de historia, una que se devora a sí misma antes de extinguirse y luego revive, como el ave fénix, una vez más" (Fuentes Myself p. 16). En otras palabras, quizás existe, no obstante, la esperanza de que México pueda llevar a cabo una auténtica revolución. La muerte de Artemio Cruz no analiza eso, pero sugiere cuáles son las consecuencias cuando se traiciona a la auténtica revolución.

En el primer acto de traición de Artemio a Gonzalo Bernal está contenida la 
felonía de toda la revolución, así como también del hombre en que Artemio podría haberse convertido pero no lo hizo. Por ello es aquí que el modelo de Artemio justifica la crueldad de sus acciones. Este momento también se puede leer como el engaño de una facción revolucionaria por otra, para el propósito de ahorro o progreso propio. Así es la elite provincial/intelectual, distanciada de la oligarquía, traicionada por el campesino ambicioso quien ve una oportunidad de mantener una ventaja a corto plazo. Por consiguiente, se podría decir, es la pasión revolucionaria informada por los hechos si no la interpretación apropiada de la historia traicionada por un miembro en la Constitución. Y sucede, por puntos de vista de Fuentes, que los miembros en la elaboración, los miembros que en años futuros constituirán la clase media-alta- y gobernante de México, ganarán verdaderamente la revolución. Fuentes estudia esto en ficción. Como veremos, los historiadores han estudiado $y$ documentado el hecho.

La facción revolucionaria más exitosa gana, por supuesto, con una actitud de engaño programático. Lo cierto es que la antigua oligarquía provenía de los aristócratas españoles en deterioro quienes encontraron poder y riqueza en el nuevo mundo; ese era un tipo de corrupción. La nueva oligarquía, de la cual don Artemio es un nuevo rico y nuevo representante burgués, surge de la corrupción deliberada de un ideal que sirvió su propósito y se deterioró como un punto de reunión para las masas de México. Esto es expresado por el hermano de Catalina Gonzalo Bernal, un intelectual a quien Artemio revela como un revolucionario de una facción opositora en la lucha interna que tiene lugar entre los revolucionarios mismos. Los hombres de Villa disparan a Bernal a cambio de que Artemio les diga sobre la misión de Bernal. Este recibe el tiro, y Artemio es perdonado; él dispara al oficial que le dio a Bernal en una cuasi-venganza, sin embargo él no es el revolucionario que es Bernal:
Ahora los hombres quienes creían que el propósito de la revolución era liberar a las personas han sido eliminados. El propósito hoy es inflar a los líderes. . . Una revolución empieza a hacerse desde los campos de batalla, pero una vez que se corrompe, aunque siga ganando batallas militares ya está pérdida. Todos hemos sido responsables. Nos hemos dejado dividir y dirigir por los concupiscentes, los ambiciosos, los mediocres. Los que quieren una revolución de verdad, radical, intransigente, son por desagracia hombres ignorantes y sangrientos. Y los letrados solo quieren una revolución a medias, compatible con lo único que les interesa: medrar, vivir bien, sustituir la elite de Don Porfirio. Ahí está el drama de México (Fuentes - La muerte de Artemio Cruz, pp. 194-95).

Artemio queda afectado por la valentía de Bernal frente a la muerte, y recuerda la exactitud de las predicciones de Bernal sobre el destino de la revolución y en consecuencia, de México. Pero como señala el escritor de Guzmán, esta sórdida historia explica la corrupción, la cual supera la conexión emocional de Artemio con la decencia: "La fortuna de la guerra hace a toda traición plausible y excusable, pero el subconsciente sabe qué clase de canalla es uno, y este recuerdo se agrega al odio a sí mismo con el cual él ahora se ve a sí y el cual proyecta en su familia" (de Guzmán p. 114).

Bernal ha visto la unidad entre clases de las fuerzas que combaten a Díaz degenerarse en facciones; que no es un 
buen augurio para México, ya que implica que las personas cuyos destinos dependen del éxito de la revolución traicionarán a ésta y a México por igual. Artemio es uno de los traidores, pero él, también, ha presenciado el choque pos revolucionario de ideales, aspiraciones manipuladas para su propia conveniencia y utilidad. Todo esto lo ha llevado a un nuevo estado, a un mundo que se ha convertido en su actual forma de ser. Existe un nexo de la novela y la historia en las acciones de Artemio que es elaborado por Hart.

Las elites provinciales y la pequeña burguesía participaron a fin de derrocar una forma de gobierno dictatorial. Los trabajadores urbanos e industriales pelearon para acabar con un sistema productivo laboral represivo. Los campesinos se rebelaron para recuperar la autonomía municipal y las propiedades perdidas, su medio de producción. Esta sección transversal de la sociedad se unificó alrededor del nacionalismo para recuperar el control de los recursos básicos del país y la infraestructura económica de la dominación extranjera (Hart, p. 348).

Sin embargo, con tantas facciones ingresando a una revolución común pero por motivos propios, no es de extrañar que después de la revuelta, cada facción buscara hacer que los resultados del levantamiento se ajusten a su propia razón. Como señala Hart, "Cada grupo derrotado -agricultores, obreros industriales, y capitalistas, y. . . la Iglesiarenegoció su situación desde una posición de desventaja, obligados a conceder el poder máximo a la elite de construcción del Estado" (Hart, p. 370).

Artemio se convierte en un instrumento de la nueva elite, la cual Hart dice era esencialmente la "pequeña burguesía [que] fue el principal vencedor militar " (Hart p. 372). Artemio cae preso de todos los vulgarismos que vienen con el poder asumido a través de motivaciones de interés propio. De hecho, lo asombroso es que la revolución fue capaz de triunfar a pesar de todo. Esto explica su trato informal de su familia, sus amantes casuales, sus maquinaciones en el mundo de los negocios que consolidarán su poder en México a expensas de otros.

Como indica Hart, el éxito del México que creó la revolución se basa en parte en "la ilusión de la esperanza y oportunidad ofrecidos por el crecimiento económico para las masas de trabajadores desempleados y agricultores sin tierra, de los cuales solo un pequeño porcentaje se puede acomodar" (Hart, p. 378). Es una ironía cruel que cuando motivos personales -ya sea en el personaje de Artemio Cruz o en la organización de una facción revolucionaria disputada- se tragan los ideales de la revolución, esta misma será traicionada por la mayoría de aquellos que participaron en ella. En tal caso, los ideales se convierten en metas. Los fines se convierten en objetivos. Los propósitos se convierten en propiedades. La transformación progresiva restringe el modelo resplandeciente hasta que se trueca en un cáncer en el cuerpo político tan sencillamente como en el de Artemio Cruz. Es la ironía cruel de Fuentes casi desesperada de los ideales perdidos que permite a Artemio Cruz morir en su cama.

Sin embargo, un último puntal en este análisis sería algo que Carlos Fuentes trae entre líneas, una especie de determinismo de la herencia popular dentro del naturalismo de Émile Zola, el realismo psicológico de Honoré de Balzac, el realismo crudo de factorías inhumanas de 
Charles Dickens o el realismo sociológico de Benito Pérez Galdós que van de la mano con las teorías cientificistas del médico Claude Bernard, la positivista de Auguste Comte o la materialista de Arthur Schopenhauer que en los siglo XIX y parte del XX estaban en boga entre las más usadas en Occidente. Hispanoamérica también se define naturalista, especialmente con los trabajos originales de Eugenio Cambaceres, Sin rumbo (1885), de Manuel T. Podestá Irresponsable (1889), de Manuel Zeno Gandía, Charca (1894), de Carlos Reyles, La raza de Caín (1900) o de Federico Gamboa, Santa (1903), que recogen estos atributos novísimos del naturalismo literario y del proceso evolutivo de la narrativa en general.

\section{Con La muerte de Artemio Cruz}

El determinismo y el sentido genético de la herencia, usado dentro del naturalismo que iba de la mano con el realismo y el criollismo, reaparecen en esta novela, pero se aparta en el manejo conductor de Carlos Fuentes. A estas tendencias se las trabaja bajo prismas melodramáticos exteriores, uniformes y llegaban a traslucirse como caricaturas: individuos buenos 0 malos. En La muerte de Artemio Cruz, el autor conserva, de una manera general, esta propensión, pero la eleva a un signo interior de concienciación y de análisis; el individuo conserva su "persona" y sus reacciones ontológicas. A Artemio Cruz se lo muestra como un ente sensor de circunstancias propias: hijo de esclava con limitaciones sociales, pero anhelante de grandeza, que va acompañada con un gran porte viril que reconquista lo heroico de un carácter ficticio convencional (Aguilar Monsalve, p. 244).
Igualmente, hay otro lado interpretativo y es el económico-político de las posiciones de izquierda y el afianzamiento de la ex Unión Soviética en los finales y comienzos de las décadas de los cincuenta y sesenta. Además, en estas épocas, las viejas tendencias de antaño todavía conspiraban para el atraso perenne de la región: alianzas mezquinas de supervivencia impuestas por gobiernos populistas, huasipungos y latifundios, supremacías económicas y políticas tradicionales y más males que habían sido tratados tanto en el ensayo como en la narrativa de años anteriores. Con esto también va el concepto determinista de fondo que hacen de La muerte de Artemio Cruz, se vuelve a repetir, una obra de corte naturalista en medio siglo XX por la relatividad de su enfoque. La codicia por el poder y la inclinación concupiscente y corrupta le vienen subconscientemente a Artemio cruz como parte general del género humano, que él no puede controlar, porque no se da cuenta y no puede distinguir entre moralidad y falta de ella. Lo que se hereda está presente; se comporta como su padre Atanasio, ambos usan a sus semejantes para su propio beneficio. Al transcurrir de los años, la familia pierde el poderío de antes y Artemio Cruz será la esperanza del regreso a los buenos tiempos, por lo menos en los ojos cansados de su abuela, Ludivinia Menchaca. Cruz pasa por altos y bajos dentro de lo económico y político. Es tentado por una reivindicación social, pero no le interesa y se une a los Bernal para recuperar su prestigio y su modus operandi de antes. Va en contra de los juaristas que buscan cambio y justicia social y se alinea al grupo de Porfirio Díaz que representa una oligarquía tradicionalista y de lleno un engaño a los ideales de la Revolución Mexicana. 


\section{BIBLIOGRAFÍA}

AGUILAR MONSALVE, Luis (2013). Breve historia de los movimientos literarios en Hispanoamérica: del romanticismo al posmodernismo, Quito, Editorial Ecuador.

DE GUZMÁN, Daniel (1972). Carlos Fuentes. Twayne's World Authors Series 151, New York, Twayne.

FUENTES, Carlos (1962). La muerte de Artemio Cruz, México, Fondo de Cultura Económica.

---(1958). La región más transparente, México, Fondo de Cultura Económica.

--- (1988). Myself with Others: Selected Essays, New York, Farrar, Straus and Giroux.

HART, John Mason (1987). Revolutionary Mexico: The Coming and Process of the Mexican Revolution. Berkeley, University of California.

REYES, Alfonso. Visión de Anáhuac, México, Editorial Joaquín Mortiz. Editorial Planeta. 